\title{
AVANCES Y APLICACIONES EN EL ESTUDIO DEL ADN DE RESTOS PALEONTOLÓGICOS
}

\author{
Neskuts IZAGIRRE y Concepción de la RÚA \\ Euskal Herriko Unibertsitatea (U.P.V./E.H.U.). Zientzi Fakultatea. Animali \\ Biologia eta Genetika Saila. Posta Kutxa, 644. 48080 BILBO (España). \\ e-mail: ggpruvac@lg.ehu.es
}

Izagirre, N. y Rúa, C. de la. 2001. Avances y aplicaciones en el estudio del ADN de restos paleontológicos. [Progress and applications in the study of DNA from palaeontological remains.] Revista Española de Paleontología, 16(1), 89-97. ISSN 0213-6937.

\begin{abstract}
In recent years ancient DNA (aDNA) work has consolidated in a field with well defined purposes. Thus, it has been possible for instance, to give some answers to archaeological or palaeontological questions such as the phylogenetic relationships between extinct species and their extant descendants, to analyse the genetic variability of populations across time or infer past demographic changes, migratory routes etc. All this has been possible thanks to the advances in molecular biology, mainly to the development of the Polymerase Chain Reaction (PCR).

But despite all this progress, aDNA analysis finds some limitations, mainly, the high risk of contamination with modern DNA and the poor preservation of DNA from ancient tissues. Environmental conditions (temperature, humidity and $\mathrm{pH}$ ) rather than time itself seem to be the critical parameters on the preservation of these samples, although it is unlikely that DNA will survive chemical degradation beyond 100,000 years. However, attempts to reproduce these results have not been successful. The oldest authentified sequences up to now correspond to a 50,000 years old mammoth and a Neandertal fossil of 100,000 years old. The latter has been a landmark in the history of this field. The study of tissues preserved in museum collections allows the phylogenetic relationships analysis between extinct (moa, kiwi, quagga, ...) and extant species. From a populational point of view, up to the present aDNA studies, are focused essentially in the colonization of America and Polynesia and the discussion about the origin of mtDNA variation in Europe. In this regard, our research on prehistoric populations from the Basque Country refutes a proposed hypothesis based on modern genetic data about the population movement ocurred in the Upper Palaeolithic.

The relevance of the inferences obtained so far, emphasize the importance of the optimization and development of these techniques. This will enable a new approach in the study of museum collection specimens which eventually shed new light on old palaeontological and archaeological questions.
\end{abstract}

Keywords: Ancient DNA, PCR, sequencing, palaeontological remains, phylogenies.

\section{RESUMEN}

En los últimos años, los trabajos con ADN antiguo se han ido conformando en un campo de investigación con unos objetivos bien definidos: las relaciones filogenéticas entre especies extintas y sus descendientes actuales, el análisis de la variabilidad genética poblacional a lo largo del tiempo o los cambios demográficos acontecidos en algún momento de su historia. Todo ello ha sido posible gracias a los avances de las técnicas de biología molecular y principalmente al desarrollo de la Reacción en Cadena de Polimerasa (PCR). A pesar de todos estos avances técnicos, el análisis del ADN antiguo se encuentra con algunas limitaciones, siendo las más importantes: el alto riesgo de contaminación con ADN actual y el deficiente estado de conservación del ADN procedente de tejido antiguo.

Sobre el estado de conservación del ADN recuperado, parece que las condiciones ambientales (temperatura, humedad y $\mathrm{pH}$ ) tienen mayor influencia que la antigüedad del material, aunque no parece probable que el ADN sobreviva al proceso de degradación química más allá de 100.000 años. Las secuencias más antiguas autentificadas que se conocen hasta el momento, corresponden a un mamut de 50.000 años de antigüiedad y a un fósil de neandertal de unos 100.000 años de antigüedad. Este último trabajo ha marcado un hito en la historia de este campo de investigación. El análisis de los restos de especies preservados en colecciones de museos, 
normalmente de menor antigüedad, permite dar respuesta a cuestiones paleontológicas tales como relaciones entre especies extintas (moa, kiwi, quagga, ...) y actuales. En el ámbito poblacional, los estudios de ADNa existentes hasta el momento se han centrado fundamentalmente en el poblamiento de América y de Polinesia, y en la discusión sobre el origen de la variabilidad del ADNmt en Europa. En este último ámbito se ha centrado nuestra investigación sobre poblaciones prehistóricas del País Vasco, lo que ha permitido rebatir hipótesis basadas en datos genéticos actuales sobre supuestos movimientos poblacionales acontecidos en el Paleolítico Superior.

El éxito obtenido hasta ahora recomienda dirigir la investigación hacia la optimización y desarrollo de las técnicas de extracción y amplificación de ADN en muestras paleontológicas de gran antigüedad, lo que nos permitirá abordar cuestiones filogenéticas hasta ahora impensables.

\section{Palabras clave: ADN antiguo, PCR, secuenciación, restos paleontológicos, filogenias.}

\section{INTRODUCCIÓN}

La historia evolutiva de las poblaciones es un complejo proceso de genealogías, cambios demográficos y adaptación al ambiente. La genealogía y los cambios demográficos se describen óptimamente mediante el análisis de los caracteres genéticos neutros. Los rasgos fenotípicos, tales como los caracteres morfológicos, nos permiten reconstruir cuales han sido los procesos adaptativos por los que ha pasado una especie a lo largo de su historia evolutiva. Sin embargo, durante mucho tiempo, el análisis de la historia evolutiva de las especies extintas sólo se ha podido realizar empleando los rasgos fenotípicos de los restos biológicos recuperados, en cuya expresión interviene el ambiente en gran medida. Con los datos morfológicos, las semejanzas halladas entre dos especies pueden deberse o bien a un origen común, o bien a adaptaciones a un ambiente similar.

Las primeras aportaciones genético-moleculares han venido paulatinamente de la mano del análisis de la composición genética de las poblaciones actuales, con ello es tan solo posible la reconstrucción de la historia evolutiva de aquellos linajes que han sobrevivido hasta nuestros días desde un último, más o menos reciente, antecesor común. Desde hace algunos años, sin embargo, es posible la recuperación y análisis de $\mathrm{ADN}$ de restos fósiles (ADNa). Aunque en principio estos estudios se han limitado al ADN mitocondrial (ADNmt), han permitido la caracterización genética de las poblaciones pretéritas de una especie a lo largo del tiempo. Las secuencias obtenidas de extractos de ADNa suponen una información importante que se puede emplear en la construcción de árboles fílogenéticos, complementando al análisis de los caracteres morfológicos.

La recuperación de información molecular tiene sus antecedentes en la aplicación de técnicas inmunológicas a animales extintos, con la finalidad de caracterizar las pequeñas cantidades de proteínas recuperadas de pieles, dientes o huesos, de especímenes preservados en museos.

Prager et al. (1980), empleando antisueros monoclonales obtenidos del músculo de un mamut, llevaron a cabo la primera comparación de una especie extinta y una actual. Estos autores observaron una fuerte reacción de dicho antígeno con los elefantes africano e indio y débil con otras especies, como la foca marina. Siguiendo esta metodología, Lowenstein et al. (1981) pudieron agrupar al lobo de Tasmania, extinto en 1933, con los carnívoros marsupiales australianos, en lugar de con especies morfológicamente similares de Sudamérica. Sin embargo, las técnicas inmunológicas en restos antiguos presentan dificultades a la hora de interpretar las reacciones serológicas con antígenos que se han modificado por procesos desconocidos (Pääbo et al., 1989).

\section{ADN EN RESTOS ANTIGUOS}

La mayor parte del material genético de un organismo se encuentra localizado en el núcleo de la célula en forma de cromosomas. Los cromosomas se encuentran formados por unos 3.000 millones de nucleótidos, que corresponden a unos 50.000-100.000 genes, pero la mayor proporción del ADN es no codificante, por tanto selectivamente neutro o casi neutro. Son estas secuencias neutras las que resultan más útiles para llevar a cabo los análisis genéticos comparativos, ya que al no estar sometidos a ninguna fuerza evolutiva, los cambios acumulados entre dos secuencias diferentes a lo largo del tiempo reflejarán el grado de divergencia evolutiva entre ellas.

También encontramos moléculas de ADN en cloroplastos y mitocondrias, orgánulos que se encuentran en el citoplasma de las células vegetal y animal, respectivamente y que se encargan de proporcionar energía a la célula. En el caso de la mitocondria, su ADN tiene una longitud aproximada de $16.500 \mathrm{pb}$, lo que supone un $0,0005 \%$ del genoma nuclear humano. El genoma del ADNmt se encuentra completamente secuenciado en humanos y en un gran número de vertebrados (Anderson et al., 1981, 1982; Bibb et al., 1981). La mayor parte del genoma mitocondrial codifica proteínas que intervienen en la división del propio orgánulo, salvo una pequeña región de unos $1.100 \mathrm{pb}$ de longitud, no codificante, denominada región control, donde los cambios, en ausencia de presiones selectivas, se acumulan de un modo mucho más rápido y en función del tiempo. Por ello, es una región útil a la hora de analizar la historia evolutiva reciente de las poblaciones, ya que incluso en periodos de tiempo muy cortos se habrán acumulado cambios.

A diferencia del ADN recuperado de organismos vivos, el ADN recuperado de restos biológicos de cierta 
antigüedad [denominado de ahora en adelante ADN antiguo (ADNa)], presenta una serie de peculiaridades que hacen que la extracción, manipulación, examen e interpretación de los resultados requieran de una mayor complejidad metodológica.

- La cantidad de ADN recuperado de restos biológicos de cierta antigüedad es muy baja lo que dificulta en gran medida su análisis; supone entre el 0,1$1 \%$ del ADN que esperaríamos encontrar en una muestra moderna.

- Otro rasgo que presenta el ADNa es que se encuentra degradado en fragmentos de pequeño tamaño, de alrededor de 100 pares de bases (pb) de longitud (Hagelberg et al., 1989). Ello nos obliga a trabajar con fragmentos de ADN pequeños comparados con los empleados en las filogenias moleculares de organismos vivos, donde se pueden llegar a amplificar miles de pares de bases de una sola vez.

Esta degradación del ADNa se debe a reacciones de oxidación e hidrólisis que empiezan inmediatamente después de la muerte del organismo (Höss et al., 1996b; Lindahl, 1993). La degradación del ADN genera segmentos o secuencias cortas, donde las moléculas de ADN se hallan enlazadas de modo poco convencional, y algunas bases nucleotídicas además se encuentran modificadas o incluso ausentes, dejando espacios vacíos en la cadena de ADN. Para una mejor conservación del ADN, resulta crítico que, inmediatamente después de la muerte, el tejido quede "protegido" en un ambiente anóxico y seco (Lindahl, 1993). Una vez que los restos se han desecado, el ADN puede permanecer relativamente estable durante miles de años (Kelman y Moran, 1996).

Se ha estimado que el genoma humano se puede degradar en fragmentos del orden de unos 100 pb en unos pocos miles de años (Pääbo y Wilson, 1991; Lindahl, 1993; Höss et al., 1996b). Lindahl (1993) afirma que teóricamente es imposible que el ADN sobreviva al proceso de degradación química más allá de 100.000 años.

\section{PRIMEROS TRABAJOS CON ADN ANTIGUO}

La disciplina del ADNa como tal tuvo su verdadero inicio cuando Higuchi et al. (1984), tras recuperar y clonar el ADN extraído de tejido muscular desecado, obtuvieron una secuencia de un équido africano, el quagga (Equus quagga), extinguido hace aproximadamente 150 años. Fue además el primer caso en el que se establecieron relaciones evolutivas, basadas en datos genéticos, entre una especie extinta (el quagga) y sus parientes vivos más cercanos (las cebras).

Paralelamente, Pääbo (1985) había comenzado a recuperar ADN de momias egipcias (2.370-2.160 a.C.). En estos años, también se investigaron, entre otros: restos de mamut de 10.000-50.000 años de antigüedad, preservados en condiciones de congelación (Johnson et al., 1985; Hagelberg et al., 1994), tejido de cerebros humanos de 7.000 años de antigüedad, preservados en ambientes húmedos (Doran et al., 1986), semillas de plantas de hasta 3.400 años de antigüedad, halladas en yacimientos arqueológicos (Rogers y Bendich, 1985;
Rollo, 1985) y preparaciones recientes de materiales de museo (Goelz et al., 1985).

De esta forma quedaba demostrada la posibilidad de recuperar $\mathrm{ADN}$ de restos antiguos, en los que se podían aplicar técnicas de biología molecular (hibridación, clonación, ...). Sin embargo, todos estos trabajos se encontraron con numerosas dificultades técnicas; así, por ejemplo, en el caso de la clonación, la maquinaria de reparación de la bacteria huésped puede reparar erróneamente las moléculas de ADNa degradadas, creando artefactos de clonaje y una baja eficiencia, lo que limita en gran medida las posibilidades de un análisis adecuado (Higuchi et al., 1987; Pääbo et al., 1989).

\section{REACCIÓN EN CADENA DE LA POLIMERASA (PCR)}

El descubrimiento de la reacción en cadena de la polimerasa (PCR) resultó providencial (Mullis y Faloona, 1987). La PCR es una técnica de síntesis enzimática del ADN in vitro que ha revolucionado el campo de la biología molecular y que le valió a Kary Mullis el premio Nóbel de química en el año 1993.

Mediante esta técnica, las moléculas de ADN molde que deseamos analizar son copiadas un número suficiente de veces para generar una cantidad de dichas moléculas adecuada para su análisis posterior. La PCR es un proceso cíclico que consta de 3 fases. En una primera fase, se lleva a cabo la desnaturalización (o separación) de las dos cadenas de ADN de la molécula molde, para ello las moléculas de ADN molde se encuentran disueltas en una solución que contiene los componentes necesarios para esta reacción, que se lleva a cabo a una temperatura de $95{ }^{\circ} \mathrm{C}$, para que se produzca la separación de ambas cadenas. A continuación, dos "cebadores" o primers (secuencias cortas de ADN complementarias al segmento de ADN molde en ambos extremos 5') presentes en la solución de reacción de la PCR, y previamente diseñados para delimitar el fragmento que se quiera analizar, se hibridan al ADN molde, lo que requiere la reducción de la temperatura a aquella que resulte específica para el anillamiento de cada par de cebadores. Tras dicho anillamiento, en una tercera fase, la enzima ADN polimerasa, en sus condiciones óptimas de temperatura $\left(72{ }^{\circ} \mathrm{C}\right)$, irá añadiendo nucleótidos complementarios a la cadena sencilla de ADN molde desde el extremo 3' del cebador.

Así, al final de este primer ciclo, habremos duplicado el número de copias de la secuencia de la molécula de ADN molde. El producto de un ciclo actúa como sustrato del ciclo siguiente, por lo que la cantidad de cadenas de ADN se duplica en cada ciclo. La cantidad de producto aumenta de forma exponencial, dependiendo del número de ciclos que se lleven a cabo (entre 30-40), podemos tener entre $2^{30}-2^{40}$ copias.

Gracias a la PCR, podemos amplificar cualquier fragmento de ADN filogenéticamente informativo, una vez diseñados los cebadores adecuados (obviamente, para ello es necesario conocer previamente la secuencia de la 
región a amplificar). Dado que la PCR es capaz de llevar a cabo la amplificación a partir de una baja cantidad de moléculas de ADN, incluso de una única copia y que además amplifica preferencialmente moldes de ADN intactos, es posible obtener cantidad suficiente de ADN de tejido antiguo para llevar a cabo un análisis electroforético o de secuenciación.

El desarrollo de la técnica de la PCR abrió nuevas vías para los análisis filogenéticos y de variabilidad genética de las poblaciones a lo largo del tiempo. Pääbo et al. (1988), aplicando esta técnica, obtuvieron la primera secuencia de un pequeño fragmento de ADNmt a partir de tejido cerebral de 7.000 años de antigüedad, hallado en el yacimiento de Little Salt Spring (Florida). Esta técnica también ha facilitado extender el análisis de ADNa a otro tipo de tejidos, como el hueso (Hagelberg et al., 1989) o el diente (Hänni et al., 1990). Al ser los restos óseos y dentarios evidencias frecuentemente recuperadas en las excavaciones arqueológicas, se abrieron grandes posibilidades en el campo del ADNa para el estudio de la historia biológica de la humanidad.

\section{EL ADN MITOCONDRIAL}

El bajo número de moléculas de ADN recuperadas en los extractos antiguos ha obligado a la mayoría de los investigadores, aunque no a todos (Bonné-Tamir et al., 1986; Lawlor et al., 1991; Martínez de Pancorbo et al., 1995; Zierdt et al., 1996), a trabajar con ADN mitocondrial (ADNmt), ya que existen miles de copias de esta molécula por célula, lo cual facilita su supervivencia y recuperación. Por otro lado, el ADNmt también presenta una serie de características que hacen de él un marcador ideal para los estudios filogenéticos y poblacionales, tanto en humanos como en otros organismos:

1.- Su tasa de cambio evolutivo es muy elevada en comparación con el ADN nuclear. El ADNmt presenta una gran variabilidad de un individuo a otro, acumulando cambios en su secuencia nucleotídica de forma rápida. En concreto, la región control engloba casi el $90 \%$ de la variabilidad total del genoma mitocondrial.

2.- Su variabilidad genética se puede interpretar de forma relativamente directa, al no estar enmascarada por el intercambio de material genético entre cromosomas homólogos (recombinación), a diferencia de lo que ocurre en el caso de los genes nucleares. Así, el ADNmt permite trazar genealogías de un modo más directo que en el caso del ADN nuclear.

3.- Dada su herencia exclusivamente materna, el ADNmt se comporta como una molécula haploide (no existen dos copias homólogas, cada una proveniente de cada parental, como en los genes nucleares, sino que todas las moléculas de ADNmt de un organismo descienden del pool materno). Esta característica supone una reducción del tamaño de la población reproductora a la mitad, por ello, el efecto de la deriva genética en la transmisión de los linajes mitocondriales va a ser más marcado (Birky et al., 1983).

\section{PROBLEMÁTICA METODOLÓGICA: LA CONTAMINACIÓN}

La gran potencia amplificadora de la PCR es, sin embargo, su mayor debilidad a la hora de amplificar ADN antiguo. Así, la escasa cantidad de ADNa recuperado en las muestras paleontológicas, unido a su estado fragmentario y en ocasiones incluso químicamente alterado, provoca que cantidades traza de cualquier ADN contaminante, presente durante el procesamiento técnico en el laboratorio, se amplifiquen preferencialmente debido a sus mejores condiciones físico-químicas.

Por ello, se deben tomar una serie de precauciones que limiten la contaminación de las muestras de tejido antiguo con ADN moderno, y que no pueda conducir a inferencias erróneas. La principal medida de precaución es el aislamiento físico del espacio donde se lleva a cabo la extracción de ADN respecto a otros laboratorios donde se analicen productos de amplificación o donde se trabaje con ADN moderno de la misma especie. Asimismo, es necesario la utilización de un equipamiento dedicado exclusivamente al trabajo con ADNa y la esterilidad del material de investigación, de forma que las superficies de trabajo y el material empleado se lavarán frecuentemente con soluciones que contengan $\mathrm{HCl}$ y serán sometidos a irradiación con luz UV.

A pesar de todas estas medidas para evitar la contaminación, se deben realizar una serie de controles para detectar si ésta ha tenido lugar. La ausencia de contaminación se comprueba mediante: 1) sendos controles, uno realizado durante la extracción del ADN, consistente en una muestra, sometida a todo el proceso de extracción, pero a la que no se le añade tejido, sino agua estéril, por ejemplo, y un segundo control, durante la fase de amplificación, consistente en una muestra a la que no se le añade $A D N$, pero que contiene el resto de los reactivos, los mismos que están presentes en las reacciones de amplificación de las muestras problema, 2) análisis por duplicado de muestras diferentes del mismo individuo, que se llevarán a cabo en distintas sesiones de análisis. Para que un resultado sea aceptado como correcto, ambos análisis han de ser concordantes, y 3 ) un control de contaminación adicional, en el caso de estudiar muestras humanas, consistente en la amplificación del ADN procedente de los restos de otras especies animales recuperados en el mismo yacimiento, con el mismo conjunto de cebadores utilizados en humanos. Los cebadores, al ser específicos de humanos, no deben generar producto de amplificación en el caso de otras especies animales (O'Rourke et al., 1996).

Aunque el mayor riesgo de contaminación de las muestras antiguas son los productos de PCRs anteriores (presentes en el ambiente del laboratorio en forma de aerosoles), la muestra en sí también puede estar contaminada, tanto con el ADN de microorganismos adheridos a los tejidos, como con el ADN de los arqueólogos que los han excavado y manipulado. Si se utilizan cebadores específicos, el ADN microbiano no supone riesgo de contaminación.

La mayoría de los restos biológicos, especialmente 
aquellos que están almacenados en colecciones de museos, han estado sujetos a reiteradas manipulaciones. En ocasiones, ha sido posible demostrar la contaminación de tejidos no-humanos con ADN humano (Hagelberg y Clegg, 1991; Woodward et al., 1994). La única técnica para detectar este tipo de contaminación sería el análisis de dos muestras procedentes de dos elementos esqueléticos diferentes del mismo individuo, en dos laboratorios independientes. Este último criterio supone el traslado del material a otro laboratorio, con riesgo para la muestra, así como una mayor destrucción del material y la duplicación del costo económico y personal. Obviamente, la contaminación con ADN humano moderno es menos problemática cuando se trabaja con otras especies animales.

Es posible, sin embargo, tomar una serie de medidas para minimizar este riesgo de contaminación. Así, es aconsejable la extracción de ADN inmediatamente despues de la excavación del material, cuando la manipulación sufrida por los restos es aún mínima; el uso de casco, mangas largas, mascarilla y guantes estériles durante la excavación. Asimismo, la manipulación por parte de una única persona de los restos, tomar un registro de las personas que hayan manipulado el material, así como muestras de su ADN para que se puedan emplear como controles de contaminación cuando el resto sea sometido a estudios de $\mathrm{ADNa}$. Y por último, la protección del material en cajas o tubos estériles y almacenamiento en condiciones de temperatura y humedad que, asimismo, frenen los procesos de degradación postmortem del ADN.

\section{ESTUDIOS POBLACIONALES EN RESTOS HUMANOS ANTIGUOS}

En la actualidad, el estudio del ADN antiguo se ha consolidado como campo científico, habiéndose conseguido resultados fiables a partir de muestras de diversa antigüedad. Los estudios de ADNa en humanos han tenido como objetivo dar respuesta a preguntas concretas, tales como acontecimientos migratorios o de colonización y relaciones evolutivas entre diferentes poblaciones prehistóricas. Hagelberg y Clegg (1993) realizaron uno de los primeros trabajos en este sentido, donde planteaban una hipótesis alternativa a la colonización de la Polinesia, apoyándose en los datos genéticos obtenidos en muestras prehistóricas.

Uno de los acontecimientos más estudiados mediante el análisis del ADNa de restos humanos ha sido la colonización del Nuevo Mundo (Merriwether et al., 1994; Lalueza et al., 1997; Stone y Stoneking, 1998). Los resultados obtenidos en los diferentes trabajos no coinciden en proponer una sola ola de migración para la colonización del continente americano (Lalueza et al., 1997), aunque todos ellos observan una mayor variabilidad en las poblaciones amerindias antiguas respecto a las actuales, en las que habría disminuido como consecuencia del contacto con los europeos a finales del s. XV (Hauswirth et al., 1994).
Los estudios sobre poblaciones europeas prehistóricas son más escasos. En este ámbito, resulta interesante destacar nuestra investigación sobre diversos yacimientos prehistóricos del País Vasco (Izagirre y de la Rúa, 1999). En ese trabajo hemos analizado la variabilidad del ADNmt mediante la técnica de los RFLPs, en cuatro colecciones esqueléticas de procedencia arqueológica, que abarcan una amplia región del País Vasco y cuya cronología se sitúa entre el Neolítico y la edad del Bronce: San Juan ante Portam Latinam (Álava, hace 5.070 $\pm 150-5.020 \pm 140$ años), Longar (Navarra, hace 4.445 $\pm 70-4.580 \pm 90$ años), Pico Ramos (Vizcaya, hace $4.100 \pm 110-4.790 \pm 110$ años) y Urratxa (Vizcaya, hace $3.405 \pm 70$ años)

Los resultados obtenidos ponen de manifiesto la ausencia de los haplogrupos I, W y V en estas poblaciones prehistóricas; los haplogrupos I y W también están ausentes en una muestra de vascos actuales (Torroni et al., 1998), sin embargo, la situación del haplogrupo $\mathrm{V}$ contrasta con las frecuencias descritas en la actualidad, cuyo rango oscila entre 3,3 y $20 \%$ (Bertranpetit et al., 1995; Côrte-Real et al., 1996; Torroni et al., 1998). Estos datos genéticos sobre las poblaciones prehistóricas del País Vasco contrastan con los obtenidos en una muestra de vascos actuales, según los cuales, Torroni et al. (1998) han propuesto una posible expansión poblacional ocurrida hace 15.000 años desde el suroeste al noreste de Europa. Este proceso se relaciona con el origen del haplogrupo $\mathrm{V}$ en la región del País Vasco y su expansión hacia el noreste de Europa, coincidiendo con la difusión de la cultura Magdaleniense (finales del Paleolítico Superior).

A la vista de nuestros resultados en poblaciones prehistóricas, consideramos que la hipótesis de Torroni et al. (1998) es precipitada y poco fundamentada debido a la incertidumbre en las tasas de mutación que utiliza, al escaso número de datos poblacionales existentes actualmente y a la interpretación del registro arqueológico que estos autores hacen. Esta discrepancia en la frecuencia del haplogrupo $\mathrm{V}$ entre los grupos actuales y prehistóricos del País Vasco, podría explicarse por el efecto de la deriva genética. La mutación que define el haplogrupo V (4577 NlaIII), pudo haber alcanzado valores muy elevados en algunas regiones del País Vasco (Guipuzcoa, 20\%), por efecto de la deriva genética, en un periodo tal como el pre-mesolítico (hace $>11.000$ años), cuando el tamaño efectivo de los grupos humanos era suficientemente pequeño como para que el efecto de la deriva genética fuera apreciable. Aunque esta explicación es compatible con la datación atribuida al origen de la mutación, no es preciso recurrir a modelos migracionistas para explicar la distribución del haplogrupo V en las poblaciones indoeuropeas (Izagirre y de la Rúa, 1999).

Sin lugar a dudas, el trabajo determinante para la credibilidad del campo del ADNa ha sido la recuperación y secuenciación de un fragmento de 387 pb de longitud de ADNmt de un fósil neandertal (Krings et al., 1997). Los resultados obtenidos son de gran relevancia antropológica e indican que el precursor de Homo sapiens 
y de $H$. neanderthalensis existió hace 465.000 años, apoyando fuertemente un origen africano reciente (hace 100.000 años) de la variabilidad genética del ADNmt del hombre moderno. Asimismo, apoya la ausencia de cruzamiento genético entre ambas formas, a pesar de su convivencia. Trabajos posteriores, uno del mismo equipo, Krings et al. (1999), en el que secuencian la zona II de la región control, y un segundo de Ovchinnikov et al. (2000), donde logran la secuencia de otro fósil de neandertal del este de Europa de 28.000 años de antigüedad aproximadamente, apoyan los resultados obtenidos en el primer trabajo (Krings et al., 1997) y refuerzan su autenticidad.

Sin embargo, la historia evolutiva de una especie no se puede inferir con fiabilidad a partir de un único locus (la molécula de ADNmt, debido a su caracter no recombinante, se considera un único locus). En este sentido, la posibilidad de amplificar ADN nuclear (o de copia única), permitiría no sólo analizar un gran número de marcadores genéticos poblacionales autosómicos, sino también otra serie de genes, como el ADN de los cromosomas X e Y. Este tipo de análisis están permitiendo el diagnóstico del sexo, incluso en individuos infantiles y juveniles, en los que actualmente resulta muy difícil mediante la utilización de los métodos osteológicos clásicos (tamaño y forma de los huesos) (Faerman et al., 1995; Lassen et al., 1996; Stone et al., 1996).

Esta potencialidad de la identificación genética tiene asimismo una vertiente más aplicada, y así, hoy en día, estas técnicas se utilizan de forma rutinaria en al ámbito forense. En el campo forense se han obtenido resultados menos discutibles, ya que, normalmente, las muestras pertenecen a una escala temporal más reciente (unos pocos años de antigüedad), con lo que el ADN es más fácilmente recuperable, pudiéndose incluso analizar genes nucleares con relativa facilidad. Ejemplo de ello son algunos conocidos casos de identificación, como el de una joven asesinada hacía 10 años, siendo la primera vez que un tribunal británico aceptaba el resultado de un análisis de ADN (Hagelberg et al., 1991); la identificación de los restos de J. Mengele (el ángel de la muerte de Auschwitz) hallados en 1985 en Brasil, mediante una determinación de paternidad realizada con su mujer e hijo (Jeffreys et al., 1992) y la identificación de los restos del zar Nicolas II de Rusia y de su familia (Gill et al., 1994).

\section{RELACIONES FILOGENÉTICAS DE ESPECIES EXTINTAS}

Los trabajos con especies extintas se han centrado en el análisis de restos no muy antiguos conservados en museos (lo que facilita un mayor rendimiento de los resultados positivos), con el objeto de establecer las relaciones filogenéticas con las especies actuales.

Así, se ha podido establecer la relación entre el lobo marsupial (Thylacinus cynocephalus) y los carnívoros marsupiales australianos (Thomas et al., 1989) y entre un felino extinto, de hace 14.000 años (Smilodon fatalis) y los Felidae modernos (Janczewski et al., 1992). El trabajo de Cooper et al. (1992) desestimó una posible relación filogenética entre el moa (un pájaro gigante de Nueva Zelanda, incapaz de volar, de una antigüedad de hace 3.000-5.000 años) y el kiwi, aunque morfológicamente eran muy similares. La implicación más importante de este estudio fue concluir la pérdida de la capacidad de volar independiente en los dos linajes. Höss et al. (1996a) analizaron la secuencia de un fragmento de $1.100 \mathrm{pb}$ de longitud de un perezoso extinto hace 13.000 años (Mylodon darwiini), la antigüedad del resto y la excepcional longitud del fragmento de ADN analizado permitieron llegar a conclusiones filogenéticas sobre el origen de la vida arborícola de las especies actuales de perezosos.

Asimismo, se han analizado secuencias de ADNmt obtenidas de pieles de canguros (Dipodomys panamintinus) desecados a principios de siglo (Thomas et al., 1990), de restos de conejos recuperados en yacimientos arqueológicos de hace 1.400 años de toda Europa (Hardy et al., 1994). El análisis de la variabilidad genética de las poblaciones de conejos (Orytolagus cuniculus) permite indagar en las rutas de origen e introducción de las variantes de conejo en Europa.

La especie extinta que ha ofrecido una mayor proliferación de trabajos ha sido el mamut (Mammuthus primigenius) (Johnson et al., 1985; Höss et al., 1994; Hagelberg et al., 1994). El gran éxito obtenido en el análisis de restos de 50.000 años de antigüedad se debe a la excelente preservación de los mismos en ambientes fríos (permafrost). Todos estos trabajos han demostrado la existencia de una estrecha relación entre el mamut y el elefante indio (Elephas maximus). Además, la abundancia de los restos de mamut hallados en condiciones de permafrost hace posible el análisis de la diversidad poblacional previa a su extinción.

Resultados espectaculares, como por ejemplo la recuperación de fragmentos de ADN a partir de una hoja de magnolia fósil de 17-20 millones de años (m.a.) de antigüedad (Golenberg et al., 1990), de insectos conservados en ámbar de unos 120-135 m.a. (Cano et al., 1993), de un hueso de dinosaurio de 80 m.a. (Woodward et al., 1994), son actualmente objeto de seria crítica y escepticismo. Los intentos de extracción de ADN de una amplia gama de insectos preservados en ámbar, llevados a cabo por diferentes equipos, a fin de probar la reproducibilidad de las secuencias, han dado como resultado la existencia de secuencias contaminantes, tanto de otras especies de insectos, como humanas y bacterianas, y en conclusión, la no-reproducibilidad de los resultados (Austin et al., 1997).

El mayor esfuerzo de las investigaciones con ADNa se ha dirigido al estudio de las filogenias entre especies extintas y actuales, cambios demográficos y genealogías. Estudios que se han visto facilitados por la gran cantidad de material preservado en buenas condiciones en las colecciones de los museos.

Actualmente, algunos trabajos se han encaminado al estudio de la prevalencia de enfermedades en la 
antigüedad (Salo et al., 1994) y la reconstrucción ambiental y de la dieta, a través del ADN preservado en los coprolitos (cantidades copiosas de heces fosilizadas bien preservadas) (Höss et al., 1992; Salo et al., 1994; Kohn et al., 1995).

Salo et al. (1994) lograron secuenciar con éxito el fragmento de un gen del bacilo causante de la tuberculosis (Mycobacterium tuberculosis), a partir de los extractos de ADN obtenidos en una momia peruana de hace 1.040 \pm 44 años de antigüedad (Chiribaya Alta, Valle Osmore). Lo que viene a demostrar que la tuberculosis ya existía en el Nuevo Mundo antes de la llegada de los europeos.

La extracción de ADN a partir de coprolitos ha permitido verificar las especies a las que pertenecían dichos vestigios. Así, por ejemplo, se identificó a Nothrotheriops shastensis, perezoso terrestre, mediante la secuenciación de un fragmento de ADNmt correspondiente a esa especie y la reconstrucción de los componentes de su dieta mediante la secuenciación del ADN de los cloroplastos de las plantas ingeridas (Long y Martin, 1974). Este tipo de análisis abre la posibilidad de estudiar a la forma extinta en su entorno, ya que nos muestra una imagen detallada de la flora existente durante la época en la que vivió.

\section{PERSPECTIVAS FUTURAS}

El objetivo de este trabajo es proporcionar a los investigadores del campo de la paleontología una visión general de las aportaciones que supone el análisis del ADN recuperado de restos antiguos, así como las limitaciones técnicas asociadas a este tipo de análisis, basado en materiales normalmente degradados.

En la actualidad las investigaciones van dirigidas a la optimización y desarrollo de nuevas técnicas de biología molecular, que permitan un mayor rendimiento en la extracción y amplificación del ADNa a partir de muestras muy degradadas. Esto nos permitirá analizar marcadores genéticos nucleares, presentes en las células en una cantidad muy inferior al ADNmt, dado su menor número de copias por célula. Este tipo de marcadores nucleares nos permitirán estudiar la historia tanto de los linajes maternos (ADNmt) como paternos, obteniendo así una visión más completa de los acontecimientos demográficos ocurridos a lo largo de la historia evolutiva de una especie. Estos avances harán posible la caracterización, desde el punto de vista molecular, de un mayor número de especies fósiles, incluso de aquellas cuyas condiciones de preservación no hayan sido las óptimas.

Además, también se vislumbra la necesidad de realizar estudios acerca de la variabilidad genética existente actualmente en un número cada vez mayor de especies (tan exhaustivamente como se ha realizado en las poblaciones humanas), de modo que se diseñen estudios para el análisis de marcadores filogenéticamente informativos.

Por un lado, el análisis de fósiles directamente relacionados con cuestiones filogenéticas y demográficas puntuales, y por otro lado, la obtención de resultados reproducibles, abren nuevas puertas para el esclarecimiento de dichas cuestiones. Por ejemplo, el análisis molecular de sendos fósiles de neandertal (Krings et al., 1997, 1999; Ovchinnikov et al., 2000), ha proporcionado datos de gran interés al debate existente sobre el origen del hombre moderno, al concluir que no hubo entrecruzamientos entre neandertales y humanos modernos. Estas investigaciones, además de dar respuesta a cuestiones paleontológicas planteadas desde principios de siglo, refuerzan la autenticidad de los resultados obtenidos en el campo del ADN antiguo.

\section{AGRADECIMIENTOS}

Este trabajo se ha realizado gracias a los proyectos GN 154.310-0001-94 (Gobierno de Navarra y U.P.V./E.H.U.) y UPV 154.310-EA008/98 (U.P.V./E.H.U.).

\section{BIBLIOGRAFÍA}

Anderson, S., Bankier, A.T., Barrell, B.G., Bruijin, M.H.L., Coulson, A.R., Drouin, J., Eperon, I.C., Nierlich, D.P., Roe, B.A., Sanger, F., Schreier, P.H., Smith, A.J.H., Staden, R. and Young, I.G. 1981. Sequence and organization of the human mitochondrial genome. Nature, 290, 457-465.

Anderson, S., Bruijin, M.H.L. de, Coulson, A.R., Eperon, I.C., Sanger, F. and Young, I.G. 1982. Complete sequence of bovine mitochondrial DNA. Conserved features of the mammalian mitochondrial genome. Journal of Molecular Biology, 156, 683- 717.

Austin, J.J., Ross, A.J., Smith, A.B., Fortey, R.A. and Thomas, R.H. 1997. Problems of reproducibility -does geologically ancient DNA survive in amber preserved insects? Proceedings of the Royal Society of London B, 264, 467-474.

Bertranpetit, J., Sala, J., Calafell, F., Underhill, P.A., Moral, P. and Comas, D. 1995. Human mitochondrial DNA variation and the origin of the Basques. Annals of Human Genetics, 59, 63-81.

Bibb, M.J., Etten, R.A. van, Wright, C.T., Walberg, M.W. and Clayton, D.A. 1981. Sequence and gene organization of mouse mitochondrial DNA. Cell, 26, 167-180.

Birky, C.W. Jr., Maruyama, T. and Fuerst, P. 1983. An approach to population and evolutionary genetic theory for genes in mitochondria and chloroplasts, and some results. Genetics, 103, 513-527.

Bonné-Tamir, B., Johnson, M.J., Natali, A., Wallace, D.C. and Cavalli-Sforza, L.L. 1986. Human mitochondrial DNA types in two Israeli populations: a comparative study at the DNA level. American Journal of Human Genetics, 38, 341-351.

Cano, R.J., Poinar, H.N., Pieniazek, N.J., Acra, A. and Poinar G.O. 1993. Amplification and sequencing of DNA from a 120-135-million-year-old weevil. Nature, $363,536-538$. 
Cooper, A., Mourer-Chauvire, C., Chambers, G.K., Haesseler, A. von, Wilson, A.C. and Pääbo, S. 1992. Independent origins of New Zealand moas and kiwis. Proceedings of the National Academy of Sciences, USA, 89, 8741-8744.

Côrte-Real, H.B.S.M., Macaulay, V.A., Richards, M.B., Hariti, G., Issac, M.S., Cambon-Thomsen, A., Papiha, S., Bertranpetit, J. and Sykes, B. 1996. Genetic diversity in the Iberian Peninsula determined from mitochondrial sequence analysis. Annals of Human Genetics, 60, 331350.

Doran, G.H., Dickel, D.N., Ballinger, W.E. Jr., Agee, O.F., Laipis, P.J. and Hauswirth, W.W. 1986. Anatomical, cellular and molecular analysis of 8,000-year old human brain tissue from the Windower archaeological site. Nature, 323, 803-806.

Faerman, M., Filon, D., Kahila, G., Greenblatt, C.L., Smith, P. and Oppenheim, A. 1995. Sex identification of archaeological human remains based on amplification of the X and Y amelogenin alleles. Genetics, 167, 327-332.

Gill, P., Ivanov, P.L., Kimpton, C., Piercy, R., Benson, N., Tully, G., Evett, I., Hagelberg, E. and Sullivan, K. 1994. Identification of the remains of the Romanov family by DNA analysis. Nature Genetics, 6, 130-135.

Goelz, S.E., Hamilton, S.R. and Vogelstein, B. 1985. Purification of DNA from formaldehyde fixed and paraffin embedded human tissue. Biochemistry Biophysics Research Communication, 130, 118-126.

Golenberg, E.M., Giannasi, D.E., Clegg, M.T., Smiley, C.J., Durbin, M., Henderson, D. and Zurawski, G. 1990. Chloroplast DNA sequence from a Miocene Magnolia species. Nature, 344, 656-658.

Hagelberg, E. and Clegg, J.B. 1991. Isolation and characterization of DNA from archaeological bone. Proceedings of the Royal Society of London B, 244, 45-50.

Hagelberg, E. and Clegg, J.B. 1993. Genetic polymorphism in prehistoric Pacific islanders determined by analysis of ancient bone DNA. Proceedings of the Royal Society of London B, 252, 163-170.

Hagelberg, E., Sykes, B. and Hedges, R. 1989. Ancient bone DNA amplified. Nature, 342, 485.

Hagelberg, E., Gray, I.C. and Jeffreys, J. 1991. Identification of the skeletal remains of a murder victim by DNA analysis. Nature, 352, 427-429.

Hagelberg, E., Thomas, M.G., Cook, C.E. Jr, Sher, A.V., Baryshnikov, G.F. and Lister, A.M. 1994. DNA from ancient mammoth bones. Nature, 370, 333-334.

Hänni, C., Laudet, V., Sakka, M., Bègue, A. et Stéhelin, D. 1990. Amplification de fragment d'ADN mitochondrial à partir de dents et d'os humains anciens. Comptes Rendus de l'Academie des Sciences Paris, 310, 365-370.

Hardy, C., Vigne, J.-D., Casane, D., Dennebouy, N., Mounolou, J.-C. and Monnerot, M. 1994. Origin of the European rabbit (Oryctolagus cuniculus) in a Mediterranean island: zooarchaeology and ancient DNA examination. Journal of Evolutionary Biology, 7, 217226.

Hauswirth, W.W., Dickel, C.D., Rowold, D.J. and Hauswirth, M.A. 1994. Inter- and intrapopulation studies of ancient humans. Experientia, 50, 585-591.
Higuchi, R.G., Bowman, B., Freiberger, M., Ryder, O.A. and Wilson, A.C. 1984. DNA sequences from the quagga, an extinct member of the horse family. Nature, 312, 282-284.

Higuchi, R.G., Wrischnik, L.A., Oakes, E., George, M., Tong, B. and Wilson, A.C. 1987. Mitochondrial DNA of the extinct quagga: relatedness and extent of postmortem change. Journal of Molecular Evolution, 25, 283-287.

Höss, M., Kohn, M., Pääbo, S., Knauer, F. and Schroeder, W. 1992. Excrement analysis by PCR. Nature, 359, 199.

Höss, M., Vereshchagin, M.K. and Pääbo, S. 1994. Mammoth DNA sequences. Nature, 370, 333.

Höss, M., Dilling, A., Currant, A. and Pääbo S. 1996a. Molecular phylogeny of the extinct ground sloth Mylodon darwinii. Proceedings of the National Academy of Sciences, USA, 93, 181-185.

Höss, M., Jaruga, P., Zastawny, T.H., Dizdaroglu, M. and Pääbo, S. 1996b. DNA manage and DNA sequence retrieval from ancient tissues. Nucleic Acids Research, 24, 1304-1307.

Izagirre, N. and Rúa, C. de la 1999. An mtDNA analysis in ancient Basque populations: implications for haplogroup $\mathrm{V}$ as a marker for a major Paleolithic expansion from sothwestern Europe. American Journal of Human Genetics, 65, 199-207.

Janczewski, D.N., Yuhki, N., Gilbert, D.A., Jefferson, G.T. and O'Brien, S.T. 1992. Molecular phylogenetic inference from saber-toothed cat fossils of Rancho La Brea. Proceedings of the National Academy of Sciences, USA, 89, 9769-9773.

Jeffreys, A.J., Allen, N.J., Hagelberg, E. and Sannberg, A. 1992. Identification of the skeletal remain of Josef Mengele by DNA analysis. Forensic Science International, 56, 65-76.

Johnson, P.H., Olson, C.B. and Goodman, M. 1985. Prospect for the molecular biological reconstruction of the wooly mammoth's evolutionary history: isolation and characterization of deoxyribonucleic acid from the tissue of Mammuth primagenius. Acta Zoologica Fennica, 170, 225-231.

Kelman, Z. and Moran, L. 1996. Degradation of ancient DNA. Current Biology, 6, 223.

Kohn, M., Knauer, F., Stoffella, A., Schröeder, W. and Pääbo, S. 1995. Conservation genetics of the European brown bear -a study using excremental PCR of nuclear and mitochondrial sequences. Molecular Ecology, 4, 95103.

Krings, M., Stone, A., Schmitz, R.W., Krainitz, H., Stoneking, M. and Pääbo, S. 1997. Neandertal DNA sequences and the origin of modern humans. Cell, $\mathbf{9 0}$, 19-30.

Krings, M., Geisert, H., Schmitz, R.W., Krainitz, H. and Pääbo, S. 1999. DNA sequence of the mitochondrial hypervariable region II from the Neandertal type specimen. Proceedings of the National Academy of Sciences, USA, 96, 5581-5585.

Lalueza, C., Pérez-Pérez, A., Prats, E., Cornudella, L. and Turbón, D. 1997. Lack of founding amerindian DNA lineages in extinct aborigenes from Tierra del FuegoPatagonia. Human Molecular Genetics, 6, 41-46. 
Lassen, C., Hummel, S. and Herrmann, B. 1996. PCR based sex identification of ancient human bones by amplification of $\mathrm{X}$ - and $\mathrm{Y}$-chromosome sequences: a comparison. Ancient Biomolecules, 1, 25-33.

Lawlor, A.L., Dickel, C.D., Hauswirth, W.W. and Parham, P. 1991. Ancient HLA genes from 7,500-year-old archaeological remains. Nature, 349, 785-788.

Lindahl, T. 1993. Instability and decay of the primary structure of DNA. Nature, 362, 709-715.

Long, A. and Martin, P.S. 1974. Death of American ground sloths. Science, 186, 638-640.

Lowenstein, J.M., Sarich, V.M. and Richardson, B.J. 1981. Albumin systematics of the extinct mammoth and Tasmanian wolf. Nature, 291, 409-411.

Martínez de Pancorbo, M., Castro, A., Alonso, S., Fernández, I., Barbero, C., García-Orad, A., Izagirre, N., Iriondo, M. and Rúa, C. de la 1995. Genetic typing with HUMTH01, HUMVWA3 and HUMFES/FPS short tandem repeat loci, D1S80 variable tandem repeat locus and HLA-DQa of recent and from XII-XIII centuries spongy bone. Electrophoresis, 16, 1612-1616.

Meriwether, D.A., Rothhammer, F. and Ferrell, R.E. 1994. Genetic variation in the New World: ancient teeth, bone, and tissue as sources of DNA. Experientia, 50, 592-601.

Mullis, K.B. and Faloona, F.A. 1987. Specific synthesis of DNA in vitro via a polymerase-catalysed chain reaction. Methods in Enzymology, 155, 335-350.

O'Rourke, D.H., Carlyle, S.W. and Parr, R.L. 1996. Ancient DNA: methods, progress, and perspectives. American Journal of Human Biology, 8, 557-571.

Ovchinnikov, I.V., Götherström, A., Romanova, G.P., Kharitonov, V.M., Lidén, K. and Goodwin, W. 2000. Molecular analysis of Neanderthal DNA from the northern Caucasus. Nature, 404, 490-493.

Pääbo, S. 1985. Molecular cloning of ancient Egyptian mummy DNA. Nature, 314, 644-645.

Pääbo, S. and Wilson, A.C. 1991. Miocene DNA sequences -a dream come true? Molecular Evolution, 1, 45-46.

Pääbo, S., Gifford, J. and Wilson, A.C. 1988. Mitochondrial DNA sequences from a 7000-year old brain. Nucleic Acids Research, 16, 9775-9787.

Pääbo, S., Higuchi, R.G. and Wilson, A.C. 1989. Ancient DNA and the polymerase chain reaction. The emerging field of molecular archaeology. Journal of Biological Chemistry, 264, 9709-9712.

Prager, E.M., Wilson, A.C., Lowenstein, J.M. and Sarich, V.M. 1980. Mammoth albumin. Science, 209, 287-289.

Rogers, O.S. and Bendich, A.J. 1985. Extraction of DNA from miligram amounts of fresh, herbarium and mummified plant tissues. Plant Molecular Biology, 5, 69-76.

Rollo, F. 1985. Characterization by molecular hybridization of RNA fragments isolated from ancient (1,400 B.C.) seeds. Theoretical and Applied Genetics, 71, 330-333.

Salo, W.L., Aufderheide, A.C., Buikstra, J. and Holcomb, T.A. 1994. Identification of Mycobacterium tuberculosis DNA in a pre-Columbian mummy. Proceedings of the National Academy of Sciences, USA, 9, 2091-2094.

Stone, A. and Stoneking, M. 1998. mtDNA analysis of a prehistoric Oneota population: implications for the peopling of the New Worls. American Journal of Human Genetics, 62, 1153-1170.

Stone, A.C., Milner, G.R., Pääbo, S. and Stoneking, M. 1996. Sex determination of ancient human skeletons using DNA. American Journal of Physical Anthropology, 99, 231-238.

Thomas, R.H., Schaffer, W., Wilson, A.C. and Pääbo, S. 1989. DNA phylogeny of the extinct marsupial wolf. Nature, 340, 465-466.

Thomas, W.K., Pääbo, S., Villablanca, X. and Wilson, A.C. 1990. Spatial and temporal continuity of Kangaroo rat populations shown by sequencing mitochondrial DNA from museum specimens. Journal of Molecular Evolution, 31, 101-112.

Torroni, A., Bandelt, H.J., D’Urbano, L., Lahermo, P., Moral, P., Sellitto, D., Rengo, C., Forster, P., Savontaus, M.L., Bonné-Tamir, B. and Scozzari, R. 1998. MtDNA analysis reveals a major late Palaeolithic population expansion from southwestern to northeastern Europe. American Journal of Human Genetics, 62, 1137-1152.

Woodward, S.R., Weyand, N.J. and Bunnell, M. 1994. DNA sequence from Cretaceous period bone fragments. Science, 266, 1229-1232.

Zierdt, H., Hummel, S. and Herrmann, B. 1996. Amplification of human short tandem repeats from medieval teeth and bone samples. Human Biology, 68 , 185-199. 